\title{
Professor Zhores I. Alferov 80-year Jubilee
}

DOI: $10.1134 / \mathrm{S} 1054660 X 10250018$

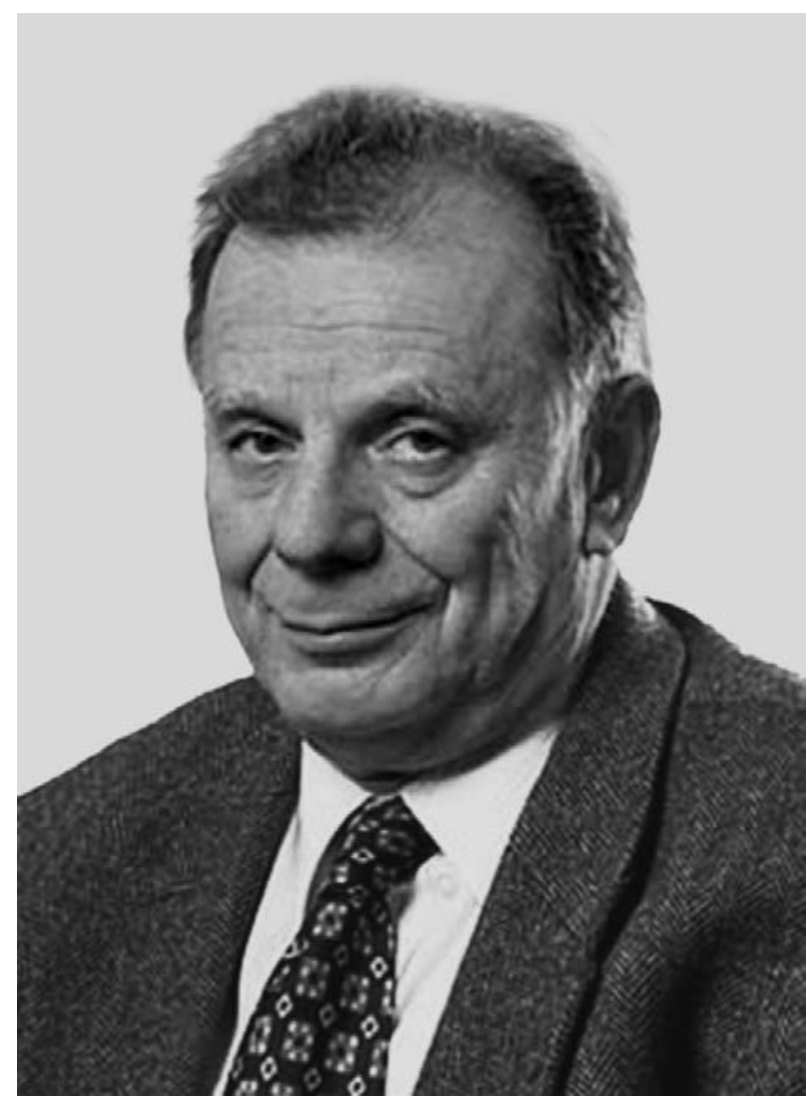

We are pleased to congratulate with 80th anniversary our senior colleague, an oldest member of the Editorial Board of the Laser Physics journal, Nobel Prize winner, academician Zhores I. Alferov.

He invented semiconductor heterostructures and developed a series of semiconductor devices, which defined a crucial progress in such important directions of the science and technology as diode and solid-state lasers optics communication, high efficient solar sells, photodetectors, and transistors.

On this jubilee we wish to Zhores I. Alferov new creative achievements and excellent health for many years to come.

Editorial Board of Laser Physics 